\title{
Editorial
}

\section{Bernhard Hommel}

Published online: 23 December 2010

(c) The Author(s) 2010. This article is published with open access at Springerlink.com

Just like with people, the continuing identity of a journal emerges through change. The changes that this journal will see in 2011 refer mainly to the editorial board. It is time to say a warm "thank you" to Jane Raymond and Akira Miyake, who did a great job in moving the journal forward in the past 2 years. And it is time to express our deepest gratitude to Carlo Umiltà, who served the journal as associate editor for so many years and, last but not least, to Herbert Heuer, who apart from many, many years as associate editor, heroically mastered the difficult job to take over the editorship from Eckart Scheerer and to successfully steer the journal between 1991 and 1995. We all owe you!

Since January 2011, the board of associate editors consists of Roberto Dell'Acqua, Karl Gegenfurtner, and Wilfried Kunde-three excellent scientists who will be able to keep the journal's high quality and open-minded attitude alive. As a team, we will continue the journal's policy to further improve speed. Our past efforts received strong and effective support from the publisher's staff and benefitted from the introduction of the new editorial system. In fact, turn-around times for submitted articles dropped to 8 weeks from submission to action letter and the publication lag has been rarely longer than 6 months. This is no reason to rest but a good first step I believe. We will also continue to explore new formats for articles and keep looking for interesting special issues, please let us know about any thoughts you might have on these topics.

Let me conclude by thanking all our loyal readers and authors and, of course, all our enthusiastic reviewers, who are so essential for maintaining the journal's high quality.

Open Access This article is distributed under the terms of the Creative Commons Attribution Noncommercial License which permits any noncommercial use, distribution, and reproduction in any medium, provided the original author(s) and source are credited.
B. Hommel ( $\square)$

Department of Psychology, Cognitive Psychology Unit,

Leiden University, Wassenaarseweg 52,

2333 AK Leiden, The Netherlands

e-mail: hommel@fsw.leidenuniv.nl 